\title{
Patient-Reported Outcome Questionnaires for the evaluation of olfactory and gustatory dysfunctions in COVID-19
}

\author{
Jerome R. Lechien ${ }^{1,2,3,4}$. Julien Hsieh ${ }^{1,5}$. Maria Rosaria Barillari ${ }^{1,6}$. Giovanni Cammaroto ${ }^{1,7}$. Stephane Hans ${ }^{1,3}$. \\ Carlos M. Chiesa-Estomba ${ }^{1,8} \cdot$ Sven Saussez ${ }^{2,4}$
}

Received: 14 May 2020 / Accepted: 22 May 2020 / Published online: 3 June 2020

○) Springer-Verlag GmbH Germany, part of Springer Nature 2020

Keywords Smell $\cdot$ Taste $\cdot$ Anosmia $\cdot$ Hyposmia $\cdot$ Loss $\cdot$ COVID-19 Coronavirus

Dear editor,

We read the letter of Passali and Bentivoglio [1] about our epidemiological study entitled "Olfactory and gustatory dysfunctions as a clinical presentation of mild-to-moderate forms of the coronavirus disease (COVID-19): a multicenter European study" [2]. The authors stated that the use of the short version of the Questionnaire of Olfactory DisordersNegative Statements (sv-QOD-NS) may bias the evaluation of the prevalence of the olfactory dysfunction (OD) in our population regarding the social anxiety, annoyance and the eating questions of sv-QOD-NS in a context of pandemic, which involves hospitalized and isolated patients.

We wish to remind that the aim of the study was to evaluate the prevalence of self-reported smell and taste loss in

Carlos M. Chiesa-Estomba and Sven Saussez equally contributed to the paper and are joint as co-senior authors.

This reply refers to the article available at https://doi.org/10.1007/ s00405-020-05999-5.

This reply refers to the article available at https://doi.org/10.1007/ s00405-020-06024-5.

Jerome R. Lechien

Jerome.Lechien@umons.ac.be

1 COVID-19 Task Force of the Young-Otolaryngologists of the International Federations of Oto-Rhino-

Laryngological Societies (YO-IFOS), Paris, France

2 Department of Human Anatomy and Experimental Oncology, Faculty of Medicine, UMONS Research Institute for Health Sciences and Technology, University of Mons (UMons), Mons, Belgium

3 Department of Otolaryngology-Head and Neck Surgery, Foch Hospital, School of Medicine, UFR Simone Veil, Université Versailles Saint-Quentin-en-Yvelines (Paris Saclay University), Paris, France the European mild-to-moderate COVID-19 patients and the majority of them were not hospitalized. The lower smell loss prevalence (25-30\%) reported by Passali and Bentivoglio could be due to differences in severity of COVID-19 population (hospitalized versus non-hospitalized).

At the time of the study conduction, there were no data supporting the recognition of the smell and taste impairments as prevalent COVID-19 disorders. The assessment of the prevalence of both olfactory and gustatory self-reported dysfunctions was based on the smell and taste component of the National Health and Nutrition Examination Survey (NHANES), [3] and not on the sv-QOD-NS, which was only used to evaluate the quality-of-life impact of OD.

NHANES is a population survey that was implemented by the Centers for Disease Control and Prevention to continuously monitor the health of adult citizens in the United States through a national representative sample of 5000 persons yearly [3]. We strongly argue that these questions covered qualitative and quantitative chemosensory symptoms encountered in smell and taste consultation. For example, the questions provided us valuable data about subjective alteration of taste perception (oral detection of salty,

4 Department of Otorhinolaryngology and Head and Neck Surgery, CHU de Bruxelles, CHU Saint-Pierre, School of Medicine, Université Libre de Bruxelles, Brussels, Belgium

5 Rhinology-Olfactology Unit, Department of Otorhinolaryngology, Head and Neck Surgery, Geneva University Hospitals (HUG), Geneva, Switzerland

6 Department of Mental and Physical Health and Preventive Medicine, University of L. Vanvitelli, Naples, Italy

7 Department of Otolaryngology-Head and Neck Surgery, Morgagni Pierantoni Hospital, Forli, Italy

8 Department of Otorhinolaryngology-Head and Neck Surgery, Hospital Universitario Donostia, San Sebastian, Spain 
sweet, bitter and sour) and aroma perception (detection of molecules flowing from the oral cavity to the nasopharynx and back to the olfactory cleft). Alteration of both, olfactory and taste function, has been further confirmed by Vaira et al. who reported patients with psychophysically measured olfactory loss without gustatory loss and vice versa [4].

In our questionnaire, we also included other questions about other ear, nose, and throat symptoms including rhinological complaints. We observed that the self-reported OD was not associated with nasal symptoms suggesting the absence of nasal inflammation, which was recently supported by the psychophysical assessments or imaging studies $[5,6]$.

Although we acknowledge that large media coverage of these symptoms in the pandemic context may lead to overestimation of self-reported chemosensory loss, we are confident that we used a reliable patient-reported outcome questionnaire to assess the prevalence of self-reported olfactory and gustatory dysfunction during the COVID-19 pandemic.

As abovementioned, the large media coverage of these symptoms in both Western Europe and US may be a factor that may support a potential overestimation of OD compared with Asia where the prevalence seems to be lower. The lower OD prevalence in Asia compared with Europe and US [7]. has been suggested in the Letter of Wee et al. [8], who reported less than $30 \%$ of OD in their COVID-19 population. In addition to the media effect, the differences between Asian and Caucasian patients (e.g., Europe and US) could be explained by polymorphisms in angiotensin converting enzyme-2 (ACE2) expression [9, 10], which is reported among European populations and could exist between world regions.

Funding This study (response to the editor) has not received any support from funding agencies.

\section{Compliance with ethical standards}

Conflict of interest The author had no conflict of interest.

Ethical approval This article does not contain any studies with human participants or animals performed by any of the authors.

\section{References}

1. Passali GC, Bentivoglio AR (2020) Comment to the article "Olfactory and gustatory dysfunctions as a clinical presentation of mild-to-moderate forms of the coronavirus disease (COVID19): a multicenter European study". Eur Arch Otorhinolaryngol. https://doi.org/10.1007/s00405-020-06024-5

2. Lechien JR, Chiesa-Estomba CM et al (2020) Olfactory and gustatory dysfunctions as a clinical presentation of mild-to-moderate forms of the coronavirus disease (COVID-19): a multicenter European study. Eur Arch Otorhinolaryngol. https://doi.org/10.1007/ s00405-020-05965-1

3. Bhattacharyya N, Kepnes LJ (2015) Contemporary assessment of the prevalence of smell and taste problems in adults. Laryngoscope 125(5):1102-1106. https://doi.org/10.1002/lary.24999

4. Vaira LA, Deiana G, Fois AG, Pirina P, Madeddu G, De Vito A, Babudieri S, Petrocelli M, Serra A, Bussu F, Ligas E, Salzano G, De Riu G (2020) Objective evaluation of anosmia and ageusia in COVID-19 patients: single-center experience on 72 cases. Head Neck. https://doi.org/10.1002/hed.26204

5. Lechien JR, Michel J, Radulesco T, et al. (2020) Clinical and radiological evaluations of COVID-19 patients with anosmia: preliminary report. Under review. Laryngoscope. https://doi. org/10.1101/2020.05.20.20106633

6. Lechien JR, Cabaraux P, Chiesa-Estomba CM et al (2020) Objective olfactory evaluation of self-reported loss of smell in a case series of 86 COVID-19 Patients. Head Neck. https://doi. org/10.1002/hed.26279

7. Kaye R, Chang CWD, Kazahaya K, Brereton J, Denneny JC 3rd (2020) COVID-19 anosmia reporting tool: initial findings. Otolaryngol Head Neck Surg. https://doi.org/10.1177/019459982092299 2

8. Wee LE, Chan YFZ, Teo NWY, Cherng BPZ, Thien SY, Wong HM, Wijaya L, Toh ST, Tan TT (2020) The role of self-reported olfactory and gustatory dysfunction as a screening criterion for suspected COVID-19. Eur Arch Otorhinolaryngol. https://doi. org/10.1007/s00405-020-05999-5

9. Devaux CA, Rolain JM, Raoult D (2020) ACE2 receptor polymorphism: susceptibility to SARS-CoV-2, hypertension, multi-organ failure, and COVID-19 disease outcome. J Microbiol Immunol Infect. https://doi.org/10.1016/j.jmii.2020.04.015

10. Coppee F, Lechien JR, Decleves AE, Tafforeau L, Saussez S (2020) SARS-CoV-2: virus mutations in specific European populations. New Microbes New Infect. https://doi.org/10.1016/j. nmni.2020.100696

Publisher's Note Springer Nature remains neutral with regard to jurisdictional claims in published maps and institutional affiliations. 